\title{
Validity of the Mindstreams Computerized Cognitive Battery for Mild Cognitive Impairment
}

Tzvi Dwolatzky • Victor Whitehead • Glen M. Doniger • Ely S. Simon • Avraham Schweiger • Dena Jaffe • Howard Chertkow

Published online: 19 March 2008

(C) Humana Press Inc. 2008

Erratum to: J Mol Neuroci (2004) 24:33-44

DOI 10.1385/JMN:24:1:033

This article, published as an invited review in the special ISOA issue of the journal, was first published as an original article in BMC Geriatrics:

Dwolatzky T, Whitehead V, Doniger GM, Simon ES, Schweiger A, Jaffe D, Chertkow H. Validity of a novel computerized cognitive battery for mild cognitive impairment. BMC Geriatrics, 3, 4-16, 2003.

The online version of the original article can be found at http://dx.doi. org/10.1385/JMN:24:1:033.

T. Dwolatzky $(\bowtie)$

Memory Disorders Clinic and Department of Geriatrics,

Shaare Zedek Medical Center,

Jerusalem, Israel

e-mail: tzvidov@bgu.ac.il

V. Whitehead $\cdot$ H. Chertkow

Department of Clinical Neurosciences,

McGill University,

Montreal, Canada

G. M. Doniger $\cdot$ E. S. Simon

Department of Clinical Science,

NeuroTrax Corporation,

New York, NY, USA

A. Schweiger

Department of Behavioral Sciences,

Academic College of Tel Aviv,

Tel Aviv, Israel

D. Jaffe

School of Public Health,

Hebrew University-Hadassah Medical School,

Jerusalem, Israel 